NOTAS

\title{
EL PLACER DE LO BUENO Y EL BIEN DE LO PLACENTERO: RETORNO ÉTICO HEDONÍSTICO A PLATÓN
}

Jorge Aguirre*

$\mathbf{V}_{\text {o }}$ oy a referirme a la ética en el mundo contemporáneo. Muy difícil el tema, tanto por la ética misma como por la multiplicidad de pensadores, líneas, corrientes, filosofías y métodos con que nos hallamos en el siglo $\mathrm{XX}$. Abordar la ética en el mundo contemporáneo puede significar, en grandes rasgos, poder abarcar alguna de las tres siguientes posiciones: a) La ética como normatividad. Es decir, la ética en su aspecto formal, preceptivo, legalista. Una ética de la fría y categórica función del deber por el deber mismo. Es la ética de postkantismo y del neokantismo; la que hemos heredado de las Escuelas de Baden y Marburgo. b) La moral, más que la ética, del utilitarismo y del hedonismo. Es la traducción de la "voluntad de poder" en aras de un auténtico rescate del hombre y

\footnotetext{
"Universidad lberoamericana.
}

su inmanencia. Esta posición puede fluctuar desde un hedonismo vulgar hasta el existencialismo más matizado. Pues el existencialismo, en un sentido noble, también es utilitarista, por lo menos en favor de cierta noción de la existencia. c) la versión analítica de la ética, que ahora comentaremos un poco más.

La versión analítica de la ética sin duda tiene como cimiento la magna obra de George E. Moore Principia Ethica. ${ }^{1}$ En mi particular opinión esta obra es la primera consideración formal sobre axiología. Si se cree que exagero, permitáseme revisar brevemente la historia filosófica de comienzos de siglo. Principia Ethica es publicada en primera ocasión en 1903, y posteriormente en una segunda edi-

\footnotetext{
${ }^{1}$ 1983, México, UNAM, Trad. Adolfo García Díaz,
} 
NOTAS

ción-por cierto, sin cambios-en 1922. Mientras E. Husserl ya había publicado Investigaciones Lógicas en 1900, y preparaba Ideas de fenomenología pura (1913), Lógica formal y trascendental para 1929 yExperiencia yjuicio para 1939. Scheler por su parte, publicaba El sentimiento en la moral en 1912, El formalismo en la ética y la ética material de los valores en 1913-1916, Esencia y forma de la simpatía en 1913, Acerca de la subversión de los valores en 1919 y De lo eterno en el hombre en 1921.

Pero obviamente, esta cronología no explica porqué es una obra de axiología, sólo indica la prioridad de su publicación. En esta obra Moore sigue el modelo newtoniano de los Principia mathematica philosophiae naturalis, pues desea constituirla en "prolegómenos a toda ética futura que pretenda presentarse como ciencia". Para ello elabora una denuncia, la cual se ha convertido en un tema clásico de nuestro siglo: el olvido del valor y del bien como géneros en lugar de valores y bienes como especies, preludiando la denuncia heideggeriana del olvido del ser por el ente-pues M. Heidegger contaba 14 años cuando se publica por primera ocasión Principia Ethica.

Tal denuncia se realiza bajo la formulación de la llamada "falacia naturalista" (o "naturista", como traducen algunos), que en su expresión más simple consiste en "identificar el bien con algo que es bueno".

Y también tiene como propósitos, según palabras del mismo Moore, descubrir los principios fundamentales del pensamiento -razonamiento- ético; establecer esos principios y, por supuesto, responder a la pregunta ¿qué es bueno en sí? Con esto considera Moore que salva los obstáculos de la falacia naturalista.

A la pregunta sobre lo bueno en sí, se pueden otorgar dos respuestas. Primeramente lo bueno en sí es indefinible y, por tanto, debemos atenernos a la intuición. Más adelante explicita: "... cuando denomino tales proposiciones 'intuiciones', pretendo meramente afirmar que son incapaces de demostración; no doy por entendido nada respecto a la manera u origen de nuestro conocimiento de ellas". ${ }^{2}$ Y la otra respuesta considera que: no hay una noción que pertenezca exclusivamente a la ética, dado que el conocimiento y la existencia de cualidades materiales son un constituyente esencial del summum bonum. Esto quiere significar, dicho llanamente, que Moore está tomando en cuenta las posiciones de empiristas y hedonistas, sobre todo las de Stuart Mill y Sidgwick.

En Principa Ethica no postula estas respuestas, sino que procede a un análisis sobre la cuestión de si lo bueno en sí es lo deseado, lo querido, lo que causa placer. Mientras que en el capítulo tercero hará una severa crítica al hedonismo, que en su expresión más esquemática, consiste en:

${ }^{2}$ Op. cit, p. ix. 
NOTAS

1. Tesis: el hedonista sostiene que "ninguna parte de la existencia humana, excepto el placer, es deseable". Luego, lo que causa placer es bueno en sí.

2. Antítesis: "el placer puede y debe distinguirse de la conciencia del placer", y cuando ocurre tal distinción, entonces:

3. Síntesis asumidora: "la conciencia del placer también es deseable", por lo que "la conciencia de cualquier estado del sujeto es deseable". Por lo tanto, no es el placer aislado de la conciencia lo único bueno en sí.

Como se percibe con claridad, resulta que el punto central de la crítica de Moore es "poder y deber" distinguir placer de la conciencia del placer. Ésta es deseable por placentera; la conciencia en sí misma es deseable. Pero ¿cómo distinguir entre placer y conciencia del placer? Y icómo saber que la conciencia es placentera? Moore, para solucionar estas cuestiones, recurre al Filebo. Es decir, opta por un retorno ético-hedonístico a Platón. (Abordaremos a éste más adelante con detalle, mientras tanto veamos otra versión de la ética analítica.)

Gilbert Ryle en una de sus obras más conocidas, Dilemas, aparecida por primera ocasión en 1954,3 y también en Plato's Progress de 1966-dig-

${ }^{3}$ Trad. Hugo Margáin y Enrique Villanueva, 1979, México, UNAM. na de atención para nuestros propósitos-aborda conflictos y soluciones inconciliables entre diversas teorías sobre un mismo problema. Dos posturas resultan inconcilibles cuando, aunque igualmente persuasivas, una nos parece repudiable -y, por tanto, preferimos la otra. Ahora bien, las preferencias se basan en teorías que discurren con iguales categorías pero en conceptos y concepciones diferentes, con nociones básicas dismiles.

Un ejemplo de estas diferencias concepcionales sobre las mismas categorías se presenta con el dilema del placer. Veamos la primera teoria que constituye un extremo del dilema: la teoría psicológica que concibe como su tarea científica la de duplicar en el mundo de la mente lo que los físicos hicieron con la materia, es decir, deseo, placer, aversión y dolor, serán términos equivalentes a presión, impacto, fricción, atracción, aceleración, etc.

Los axiomas de tal teoría son: todos los deseos mueven la conducta. Todos los deseos son deseos de placer, por lo que, toda acción está intencionada al incremento de placer y al decremento de dolor y, consecuentemente, la eficacia del placer consiste en la intensidad, prolongación y mezcla de ambos. Establecidos estos axiomas, su proposición consiste en sostener que el placer es una sensación. Y finalmente su corolario, que la sensación placentera es susceptible de variaciones cuantitativas. 
La ética que se desprende de tal sistema es totalmente mecánica; el bien sumo, o simplemente el bien, consiste en procurar placer. Éste se eleva a la medida de todas las cosas, y la prudencia consiste en su exacto cálculo, depende de la intensidad y durabilidad o la capacidad de permanencia y frecuencia.

Ryle critica a esta teoría en cuatro aspectos: Primeramente porque el placer no puede ser la contrapartida del dolor, pues el dolor se puede describir a un médico como palpitación, punzada, ardor, según lugar y frecuencia; pero el placer no lleva esta determinación. En segundo término no puede ser sólo una sensación, pues las sensaciones no pueden conocerse sin cierto grado de conciencia (no se puede disfrutar o detestar algo indistintamente, es decir, cuando disfruto, para hacerlo, tengo que saber que estoy disfrutando). En tercer lugar critica que el placer sea al mismo tiempo causa y efecto de sí mismo, vgr.: "dondequiera que hay tal acción humana, hay placer" $y$ "dondequiera que hay placer, hay tal acción humana". Finalmente dirá, el disfrute no puede ocurrir por sí sólo. El enunciado: "alguien ha estado disfrutando" por sí mismo carece de sentido, como "alguien ha estado interesado", "alguien ha estado absorto". Los verbos transitivos de estos enunciados requieren los objetos de disfrute, interés y distracción.

Como se evidencia, resulta que el punto medular de la crítica de Ryle es el segundo, el que atiende al estado en el cual el placer no puede obtenerse sin cierto grado de conciencia.

Moore y Ryle coinciden en la crítica capital al hedonismo: el placer puede constituirse en tal, bajo la condición de la conciencia. Es pues la conciencia el elemento esencial de lo placentero. Pero, cuál es la teoría que expone y defiende Ryle como contrapeso de su "dilema"?

Dice textualmente: "No obstante, tenemos aún nuestros momentos platónicos..." ${ }^{4} \mathrm{Y}$ comienza por exponer la analogía platónica entre el hombre considerado como un micromodelo del Estado y éste, su respectivo macromodelo, para discutir cuál de las vidas placenteras (la del gobernante-filósofo, la del tirano o la del comerciante) es la más auténtica. Elucida la cuestión afirmando que en los tres tipos de vida opera la misma condición para descubrir cual es la más feliz : la conciencia de sí, sometida a los criterios de experiencia, inteligencia y razonamiento. Ryle recurre a Platón, y aunque no cita directamente ninguna obra, no hay duda de que alude a la República. ${ }^{5}$ Ahí se discute esta misma cuestión debatiendo que es el filósofo quien obtiene una vida feliz auténticamente placentera, pues forzosamente en su historia personal ha tenido que experimentar los placeres del honor y del dinero, subordinándolos a los del saber, mientras

\footnotetext{
${ }_{5}^{4}$ Op. cit, p. 76.

${ }^{s} 580 \mathrm{a}-587 \mathrm{c}$.
} 
que el ambicioso y el avaro desprecian la sabiduría, ya que carecen de la experiencia y conciencia que les permita gozarla. En estos breves pasajes se preludia la discusión que posteriormente se aborda en el Filebo sobre los placeres puros o lícitos y los impuros, así como la naturaleza misma del placer. Pero en ambos Diálogos Platón sostiene el mismo criterio; es la conciencia y no la cesación del dolor "menos real" (el físico) lo que constituye en verdaderamente placenteros a los procesos que nos restauran en nuestra naturaleza. Pues la ciencia es el movimiento mas real de plenitud, dado que satisface el vacío fundamental del hombre.

Retornemos pues a Platón, desarrollando una re-lectura pausada, amplia y centrada de nuestro tema, tal como se encuentra en el capital texto Filebo o del placer, ya que la tesis central, a más de develar la naturaleza misma del placer, consiste en argumentar su posibilidad, si es auténtico, como bueno, inclusive en sentido moral.

La primera definición del placer que se somete a discusión es la postura sostenida por Eudoxio frente a Platón, en la misma Academia: el placer es el bien universal, tesis que es analizada y desechada. La razón por la cual no puede sostenerse estriba en las mismas objeciones que hemos recogido en Moore y Ryle: placer sin conciencia, no puede ser placentero.

La segunda definición estudiada proviene de Espeusipo, quien considera que el placer es la cesación de dolor, es decir, la búsqueda del equilibrio propiciado por los contrarios hasta alcanzar el estado neutro. Esta tesis es rechazada por razones que veremos a continuación.

Y la tercera definición propuesta, que parece proceder de Aristipo, fundador de la Escuela de Cirene, sostiene que el placer es génesis. ${ }^{6}$ Esta postura es adoptada y explicitada por Platón, al sostener que el placer es bueno, incluso en el aspecto moral, aunque no es el bien.

Pero el Diálogo comienza discutiendo cuál elemento debe predominar para alcanzar una vida humana más perfecta, si el intelecto con su erudición, saber enciclopédico y hábito de investigación teórica o, por otra parte, la actitud dedicada exclusivamente al deleite, el disfrute y lo gozoso. Y después de una larga reflexión se considera que el elemento predominante debe constituirlo la vida mixta, es decir, la que está mezclada de inteligencia y placer, la más digna de ser vivida por un humano. No una vida de pura intelección o erudición, ni tampoco una dedicada sólo a lo placentero. Una vida exclusiva de saber, sin deleite alguno, no es para un humano, pero, del mismo modo, una vida exclusivo de deleite, donde no intervengan la conciencia, la memoria -aunque sólo sea para reconocer y anticipar el

\footnotetext{
${ }^{6}$ Filebo, 54c.
} 
NOTAS

gozo del deleite- ni la inteligencia para procurarse un mejor cálculo de placer más intenso y perdurable, tampoco merece la pena -y ni siquiera la posibilidad-de ser vivida.

En una argumentación más detallada (el Filebo expone dos) tendríamos, en orden de prioridad, que los elementos componentes de la vida mixta son: la medida, la proporción, la belleza, el intelecto (como nöus), la verdad -emanada del intelecto-, las ciencias con su universalidad, y los placeres puros en último lugar.

Diés sostiene a lo largo de su muy erudita introducción, ${ }^{7}$ que Platón en este Diálogo deja de ser tan ortodoxo y como se nos había presentado en los Diálogos de juventud o de transición a la madurez. Y sin embargo, no deja de ser prudente. Esto explica la enorme lejanía que el placer (y apenas el placer puro) ocupa respecto al primer puesto en la lista de prioridades para la vida humana.

El Diálogo, cơmo señalé, expone dos enumeraciones para asignar una escala de valores a los elementos que deben conformar la vida mixta. Ambas escalas son deducidas a partir de la postulación de cuatro géneros supremos. Aquí, en el Filebo son:peras, como lo limitante, el fin, el límite correspondiente a la phrónesis en el hombre. Luego el apeirón como lo in-

7 Platón, Oeuvres completes, tome IX. 2a. partie, Philebe, texte établi et traduit par Auguste Diés. Sociéte D'Edition "Les Belles Lettres", Paris, 1978. finito o indeterminado, es decir, lo caótico en el universo. En tercer lugar la mezcla de ambos, consistente en lo mixto de ilimitado y limitante, que produce lo limitado, finito, "entitativo", que en términos antropológicos podemos considerar como la vida mixta y feliz; la más elegible de entre todas las posibilidades humanas. $Y$ por último, la causa de la mezcla, que es el nöus, definido como inteligencia, y para el hombre como la sabiduría.

Respecto de la mezcla elaborada con los dos primeros géneros supremos es interesante la noción de posón, como la cantidad exacta que nace de la limitación de lo ilimitado por el límite y, consecuentemente, la noción de génesin eís oúsian ${ }^{8}$-que viene enunciada en el Diálogo con mucha anterioridad, pero complementa la tercera y definitiva definición del placer, como habíamos dicho: el placer es génesis-interpretada no como la fase pasiva del oúsian ágein del Sofista ${ }^{9}$ o la del Parménides, oúsias metalambánein, ${ }^{10}$ sino como una fase activa donde el devenir se promueve hacia el ser, donde la generación se produce hacia la existencia. Al respecto Diés comenta con toda precisión:

On à fait grand état de ce génesin eís oúsia et l'on a souvent voulu y voir une telle nouveauté dans le

\footnotetext{
${ }^{8}$ Filebo, 26d.

${ }^{9} 219 \mathrm{~b}$.

${ }^{10} 163 d$.
} 
NOTAS

platonisme, qu'elle y serait comme le manifeste d'une promotion du devenir a un plus haut degré de valeiur ontologique. ${ }^{11}$

Y en eso coincide con otras de las reconocidas interpretaciones no ortodoxas del Platón posterior; por ejemplo Burnet señala:

...ese es el nuevo sentido que Platón le da al término ser (being, en el original) en ese pasaje (Filebo 25 e y ss.). La doctrina pitagórica simplemente identificó la Forma con ser y lo Ilimitado con devenir, pero Platón distingue el estado que la mixtura también es verdaderamente ser. El proceso de mixtura o mezcla es un devenir (génesis) pero éste es un devenir que tiene ser, por esto resulta génesis eís oúsia y la mixtura misma es ser, verdadero ser que posee devenir (gegéneméne oúsia). Justamente como el camino que encontramos en Timeo (35 a), que ser (oúsia) es mezcla de lo Uno y lo Otro. ${ }^{12}$

Natorp, por su parte, hace notar de modo sobresaliente que: "Es ist sehr zu beachten, dass hiermit, zum ersten Mal in dieser Deutlichkeit, das Wer-

${ }_{11}^{11}$ Op. cit., p. xxviii.

12 Burnet, J., Greek Philosophy. Thales to Plato, Macmillan, St. Martin's Press, new York, 1968, p. 269-270 en epígrafe 249. La traducción es mía. den einen ganz positiven Sinn erlangt, usw..." ${ }^{13}$ Y Robin, en sus comentarios acerca del Filebo destaca "que el devenir no está excluido de la realidad verdadera... un devenir que no se perpetúa en su devenir, pero un devenir que deba fijarse". ${ }^{14}$ Bajo este marco tendremos que considerar la definición de hedoné como génesis.

Esos cuatro géneros en el Sofista ${ }^{15}$ son: el movimiento; el reposo; la existencia, lo idéntico; y lo distinto. ¿Por qué Platón dice en el Sofista que los cuatro géneros supremos son éstos, y posteriormente en el Filebo dice que son otros? J. Lachelier, basándose en un pasaje de Plutarco, establece una correspondencia de identidad entre los géneros del Sofista y los del Filebo. ${ }^{16}$ Nosotros pensamos que no se trata de una incongruencia, pues es frecuente que Platón no recurra a la elaboración de un discurso "exacto" que, entiéndase bien, no es lo mismo que verdadero. Platón sabe que la letra mata al espíritu (vgr. encontramos una indicación en el Fedro; como el pasaje es muy largo me permitiré citar el resumen que hace Jowett en su conocida versión:

\footnotetext{
${ }^{13}$ Nartop, P. Platos Ideenlehre Ed. Düz, Lipsia, 1903, p. 308.

${ }^{14}$ Robin, L., Platon, Alcan, Paris, 1935, p. 155. La traducción es mía.

${ }^{15} 248$ ss.

${ }^{16}$ Lachelier, J. "Note sur le Philébe de Platón", en Revue de metaphysique et morale, Paris, marzo, 1902 .
} 
NOTAS

La escritura es muy inferior al recuerdo. La escritura es como la pintura: siempre está silenciosa $\mathrm{y}$, al contrario que el habla, no se la puede adaptar a los individuos. Pero hay otra clase de escritura, grabada en las tablillas de la mente. ¿Qué hombre sensato plantaría semillas en un jardín artificial, para que produjeran fruto o flores a los ocho días, y no en un suelo más profundo y adecuado? Por diversión, puede plantar sus bellos pensamientos en ese jardín, pero si su pretensión es seria, los implantará en la suya y en otras naturalezas nobles). ${ }^{17}$

También pueden verse otras referencias con respecto a la sinoúsia en mi "Conocimiento metódico y no metódico; so-pretexto para una digresión acerca de la dialéctica según Platón". 18

Lo anterior nos obliga a pensar que Platón pretende hacernos caer en la cuenta de que el movimiento, como lo describe en el Sofista, ${ }^{19}$ es real. El movimiento existe, aunque no es parte de la existencia, es decir, no pertenece a la realidad. El movimiento, dice ahí, es un género que le corresponde a la existencia, que no es ella, pero que tiene facultad para mezclarse con ella,

\footnotetext{
${ }^{17}$ Fedro 275c5-277a4.

${ }^{18}$ En Revista de Filosofta, No. 68, Universidad Iberoamericana, México, 1990.

${ }^{19}$ 248-253.
}

así como el género " reposo". Y que, sin embargo, movimiento y reposo no se pueden relacionar. Ambos reales, ninguno es la realidad. ${ }^{20}$

Ahora bien, en el Filebo, el tercer género es la "mezcla" de apeiron y peras. Es en la mezcla donde se produce la vida mixta y en ella el placer. El placer es un hecho de tipo "mixto", nacido por causa del nöus.

Notemos que Platón desea persuadirnos de que el movimiento es del género de lo mixto (pues Sofista es anterior a Filebo), ${ }^{21}$ que ambos existen aunque no sean la existencia, y que se dan por ella y en orden a ella.

Placer es mixtura, placer, en consecuencia, no puede ser el bien universal (primera tesis expuesta y refutada en el Filebo). El movimiento no es el fin. Es el camino hacia el fin, es un ser que existe en razón de la existencia, del fin, pero no es el fin. Su término se da con el fin.

Platón introduce en su argumentación una taxonomía de los placeres. ${ }^{22}$ Esencialmente lo divide en puro e im-

${ }^{20}$ Cfr. Gómez-Lobo, A. "Autopredicación", en Platón: los Diálogos tardios. Actas del Symposium Platonicum 1986, editado por la UNAM, 1987.

${ }^{21}$ En esto sigo a David Ross quien expone en Teoría de las ideas de Platón (trad. José Luis Diés Arias, Ed. Cátedra, Madrid, 1986, p. 16), una cronología de los Diálogos según estudio comparativo de los principales especialistas, donde todos coinciden en este punto: Arnim, Lutoslawski, Ritter, Wilamowitz.

22 Filebo, 52 ss. 


\section{NOTAS}

puro. Impuro es aquel cuya ausencia causa un dolor y cuya presencia lo evita. De manera que la vida placentera en este sentido será una vida neutra, donde un vacío se llena, donde la necesidad toda vez satisfecha produce el estado de anulación; no más movimiento, no más ir a cumplir nuestra finalidad, no más parecer-se al arquetipo ideal que integramente nos integra (nuestraoúsia). ${ }^{23}$ Éste es el placer que considera la segunda tentativa definitoria procedente de Espeusipo, por eso es descartada. Ejemplos de esos casos hay muchos; como el placer de la comida, del dormir y de la "comezón".

Pero por otra parte, el placer puro es aquel cuya ausencia no es dolorosa y cuya presencia es agradable. Enumera entre otros, el placer de los bellos colores, sonidos, luces y el placer de las ciencias (mathémata hedonás).

Dicha taxonomía, a mi modo de ver, parece tener dos defectos. Primeramente, considerando al placer impuro como la mengua de un dolor, sea éste el hambre, el cansancio o la "comezón", creo que debe concebirse sim-

${ }^{23}$ Para una mayor información del díficil término oúsia, son muy recomendables: Kahn, $\mathrm{Ch}$. H., "Language and Ontology in the Cratylus", en Exegesis and Argument, Van Gorcum, Aseen, 1973, p. 152-176. Schuhl, P.M., Le jougdu Bien, les liens de la nécessité et la fonction d'Hestía, en Le merveilleux, la pensée et l'action, Flammation, Paris, 1952, p. 121-122. Loriaux, R., L'etre et la forme selon Platón, Desclée de Brouwer, Paris, 1955, p. 21-34. plemente como una satisfacción. No es el bien supremo, ni el elemento de más importancia en la vida humana, como hemos dejado en claro con las dos primeras definiciones. Sin embargo, la adquisición de este sencillo -o mejor debería decir, subordinado- placer no necesita de un comer, dormir, o "rascarse" continuo para acabar con el dolor. En este sentido no veo cómo es posible considerar al placer como génesis hacia la existencia íntegra que nos integra, si tales satisfacciones, o mejor dicho, movimientos hacia la satisfacción, no pueden ser eternas, porque son necesarias pero no suficientes, y por lo mismo tampoco permanentes, dado que la clasificación de placer impuro que ahora nos ocupa se encuentra categorizada como una de las formas de lo que es el placer en sí, de acuerdo con la tercera definición. Por esto mismo indiqué que me parece mejor denominarlo placer "subordinado"; así como en la vida humana hay movimientos que son vitales en el sentido de que, si bien no son los quehaceres principales del hombre para llevarlo a su perfección, son necesarios para poder efectuar los superiores, o más cercanos a la plenitud de la realización. De este tipo de movimientos son comer, dormir y sanar, cuando las necesidades que cubren son auténticas y no falsamente creadas en el hombre y puestas fuera de su propio eidos.

Por otra parte, considerar al placer puro como aquel cuya ausencia no es 
dolorosa, implica afirmar que aquello no poseído no daña y, por tanto -aquí está mi objeción- no hay razón para poseerlo. Bien podríamos tenerlo o dejar de tenerlo y no importara en lo más mínimo para nuestras vidas. El placer puro, como el de contemplar las bellas formas esquemáticas de la geometría, o la belleza de la luz, no posee para nuestra realización ningún objetivo, no adquiere relevancia alguna. Si el placer puro no tiene ningún fin en nuestra existencia, su pureza es de una dignidad superior a la humana. El placer puro, al ser gratuito, resulta vano en su procuración.

Es muy llamativa la denominación de la ciencia (mathémata) como uno de los placeres puros. Hago notar que el texto original dice mathémata y no episteme o sophía. Aquí parece que Platón nos da un pista para que no procedamos en las objeciones que le hemos puesto. El atento lector no sólo sentirá que es llamativa la inclusión de la ciencia, sino que inclusive es sospechosa. Más aún si recordamos los pasajes de República donde ha justificado los placeres legítimos por el razonamiento y la inteligencia, y aquel otro en donde "la ciencia atrae el alma, de lo que deviene a lo que es". ${ }^{24}$ Lo placentero del saber no puede ser puro, en el sentido de lo opuesto a impuro, tal y como se ha descrito. El placer del saber está harto mezcla-

${ }^{24} 580$ ss., $521 \mathrm{~d} 3$ y $522 \mathrm{e} 6$ respectivamente. do de vacuidad, de presencia y ausencia de dolor, e incluso de necesidad.

¿Por qué hablamos de lo placentero del saber? Porque es lo que encontramos en la tercera tesis expuesta en el Filebo, ${ }^{25}$ y finalmente es lo que creemos. Pues el saber también es génesis, (tesis expuesta desde el Banquete en donde: "ninguno de los dioses filosofa, ni desea hacerse sabio") ${ }^{26}$ y la génesis se sostiene y produce necesariamente en orden a la oúsia. ${ }^{27} \mathrm{Al}$ movimiento le hemos concedido el ser. ${ }^{28}$ El placer es un movimiento que, si es auténtico, se da en orden al ser y al bien. El movimiento -se ha aclarado-no es el ser, ni por lo tanto, el bien, pero es el camino de lo bueno al bien. El placer que es movimiento se da para ser. Movimiento no sólo es dynamis, como capacidad activa de ejercer una facultad o como capacidad de recibir la acción de otro. Todo ente es dynamis, ${ }^{29}$ pero es dynamis porque es physis. Physis como movimiento hacia la oúsia. El placer, en consecuencia, es génesis, dynamis, physis, la actuación del hombre hacia su propia oúsia. Por esto mismo, Aristóteles concede en su crítica a Platón que: pása hedoné génesis éstin eís physin aísthete. ${ }^{30}$

\footnotetext{
${ }^{25} 54 \mathrm{c}$.

${ }^{26} 202 \mathrm{e}$.

${ }^{27}$ Reiterado en Filebo 54d, tal como se anticipó en 26d.

${ }^{28}$ Sofista, 248.

${ }^{29}$ Idem.

${ }^{30}$ Todo placer es una génesis consciente restauradora del estado natural, $1152 \mathrm{~b} 13$. Igual en 1152 b 34 .

Estudios 26, otoño 1991
} 
Placer es moverse existiendo para ponerse en la existencia. Todo movimiento que coadyuve y auxilie al advenimiento en el ser es placentero. "Conservarse en el ser y alejarse de la nada" es el cometido de laphysis. Conservarse en el ser quiere decir ejercer la dynamis, la cual nos lleva a la areté, como se desprende del ejemplo acerca del medicamento que encontramos en el Diálogo Cármides. ${ }^{31}$.

El placer no es el bien, así como Eros no es la perfección; pero puede ser bueno, así como Eros es bueno, porque son movimiento hacia el bien. El placer que se mueve hacia la oúsia es el movimiento del saber; tal como lo anunció Platón cuando afirmaba: "tiene placer el sabio en la práctica misma de la sabidura", ${ }^{32}$ "el hombre prudente halla su goce en la moderación". 33

El movimiento placentero, restaurador de nosotros mismos, es impuro, porque la virtud no es el automovimiento de la perfección. Es impuro ya que el hombre resulta insuficiente ontológicamente (no se puede mover a sí mismo). El hombre consiste en una paradoja inacabada y por acabar-se. Es impuro así como Eros no es ni divino ni humano, sino hijo de Penía y Poros. El placer, entonces, es hijo del

31 156b. Cfr. mi trabajo sobre La nocion de 'areté en los Diálogos de Platón, Universidad Iberoamericana, México, 1985.

${ }^{32}$ Filebo, 12-13.
${ }^{33}$ Idem. movimiento y del reposo, según nuestra interpretación del Sofista; de apeiron y peras según el Filebo. El placer de la virtud es un erótico movimiento producido hacia la existencia.

La impureza de este placer auténtico, para decirlo con otras palabras, consiste en que su movimiento es la fundación delperas en el apeiron, de la unidad en lo multiple. Si moverse hacia la íntegra existencia de sí mismo es placentero, es porque con este movimiento deseamos no movernos. Si el placer es buscado para satisfacer una necesidades porque se desea realizarse. No es mero juego inútil como el movimiento de la moda. Es movimiento por mover-se, para conseguir el "se"; el se implica el soy, y éste al ser y al no-ser. Al no ser, porque sin éste ¿por qué -o mejor dicho, desde dóndemover-se?

Placer impuro porque el hombre tiene un hambre de saber, que es añoranza de ser, se encuentra ávido de su propia completud. Tal necesidad es provocada por su insuficiencia ontológica, por su contingencia, pues no puede saber-se, ni mover-se, a sí mismo, sino es por otro, que es el uno, el mismo. Su contingencia es el dolor originario de la humanidad. El dolor de la ausencia, pero no la ausencia de lo que nunca se ha poseído. Lo que nunca se ha poseído, no duele. Es el dolor del olvido; de lo poseído y perdido. De ahí que la anámnesis sea placentera.

Bien podemos concluir afirmando que si la auténtica génesis es anámne- 


\section{NOTAS}

sis de oúsia, entonces lo único auténticamente placentero es la búsqueda de sí mismo, que consiste en entregarse a la virtud. 